\title{
Mediating Social Network Education Teaching OOP
}

\author{
Elias Vidal Bezerra Junior ${ }^{1, *}$, Alex Sandro Gomes ${ }^{2}$, Flavia Veloso Souza ${ }^{3}$ \\ ${ }^{1}$ Coordination of Computing, IFTO, Porto Nacional, Brazil \\ ${ }^{2}$ Centro de Informática, UFPE, Recife, Brazil \\ ${ }^{3}$ Department of Mathematical Sciences, UFPB, Rio Tinto, Brazil \\ *Corresponding author: evbj@cin.ufpe.br
}

Received April 16, 2013; Revised May 06, 2013; Accepted March 31, 2014

\begin{abstract}
This article examines the practice of teaching object-oriented programming technology through social networking educational Redu and presents the functional requirements for improving the process of teaching. Observations were done in the classroom and online. Preliminary results indicate that social networking has proved to be an innovative teaching method and presents itself as an effective tool helping teachers in educational practice.
\end{abstract}

Keywords: object-oriented programming, collaboration, education

Cite This Article: Elias Vidal Bezerra Junior, Alex Sandro Gomes, and Flavia Veloso Souza, "Mediating Social Network Education Teaching OOP.” American Journal of Educational Research, vol. 2, no. 4 (2014): 204207. doi: 10.12691/education-2-4-5.

\section{Introduction}

The programming language courses in this content areas are related to computing. Introductory disciplines to programming language require students to develop skills of logical reasoning, problem solving and abstraction [1]. According to [2] the paradigm of Object Oriented Programming (OOP) is a fundamental topic in Computer Science, as is most present in different languages and programming environments in use today $(\mathrm{C}++$, Java, $\mathrm{C} \#$, Python, Ruby, PHP, Perl). The OOP has been seen as not only fundamental content of computer courses but also courses in the area of technology such as engineering [4].

To [3] the big problem in teaching OOP is not the object-oriented paradigm, but the lack of tools and environments that can support teaching practice. Tools and environments available for teaching OOP are usually very complex and difficult to navigate both by teachers and by the students. Researches have been developed, such as [12], in order to develop methods and environments that support the teaching of OOP.

In this study, we sought evidence that would allow us to conclude whether the use of a social network can improve the educational practice of teaching OOP. The assumption that a collaborative environment can support the teacher in teaching OOP since it provides a description of contents, availability of resources to use the programming language within the environment, and presents the possibility of application testing with exercises to fix content, among other features. Thus the use of such a collaborative platform could support the teacher's teaching practice and provide students and teacher interaction beyond time and space of the classroom.

This research aims identify the requirements from the needs with the use of social networking in Educationspecifically about teaching practices of Object Oriented
Programming (OOP). The identification of needs is intended to enable the teaching practice in Redu, in Object Oriented Programming is as simple and effective. From the survey of requirements we'll be able to identify features that help teacher to examine the practice of planning, teaching and assessment to improve the effectiveness of their activities. For this, we will examine the teaching practice in the environment of an educational social network.

This paper is structured as follows. Section 2 presents the use of collaborative environments in teaching Object Oriented Programming and Collaboration. Section 3 presents the Redu educational social network, environment used for teaching OOP. Section 4 deals with the method. Section 5 presents the first results obtained and a discussion about them. In section 6 will show the Functional Requirements Established and finally section 7 presents the conclusions and future work.

\section{Teaching OOP in Collaborative Environments}

Teaching programming and modeling using objectoriented methods has become common in the introduction of computer science for the last ten years. The POO, [18] is a new way of thinking about the process of decomposing the problem and develop programming solutions. Some research indicates that learning the paradigm of object oriented programming is more difficult than other paradigms [19].

Several alternatives have been considered to support the teaching of OOP such as learning based games [12], and the creation of teaching methodologies such as OOP iPoo [20] and the mode of teaching learning in Cyclo [5]. The virtual learning environments have been seen as tools that can provide alternative and complementary collaborative 
learning experience. Communication, coordination and cooperation are essential elements for the realization of a collaborative activity. The communication directs the action and must be done in order to negotiate and exchange information with other members. Coordination must occur before the activity is started-through planning, and during the execution of tasks, so that the activity is carried out successfully. The cooperation will occur during the joint realization of the tasks required to complete an activity is defined as an activity of exchanging information in a group whose members are responsible for their own learning, but are encouraged to participate in the learning process of others members. Thus, each member acts as the manager of their learning process and as an active participant in the learning process of the other members. This takes teachers to interact more intensively with students during the teaching of OOP. Thus collaboration creates new opportunities for learning among students, which can benefit the use of tutoring in a language [9].

The collaborative teaching mediated or collaborative learning environment-e-learning-is an instructional method through which many students are grouped virtually in order to achieve a common academic goal. Students may come from different places. The purpose of the collaborative e-learning is to promote the group as a whole, fostering the features of each individual use. So when in a group, these resources can be made available for the best use of all members [7].

Thus, each member can use various resources available in the group, thus enriching their knowledge, which is not possible individually. For [8], the main features of an elearning collaborative environment are:

1. Heterogeneous Grouping-Students, each distinct from each other on various parameters to work with the other;

2. Interaction between the parties-Students who need help, begin to interact with their peers, which can solve your purpose;

3. Individual responsibility-Each member is encouraged to share their knowledge with other group members;

4. The positive interdependence-Each member given the opportunity to share their experience with others, begins to feel that he/she is important and that all together are needed to succeed;

5. Skills-Cooperative cooperation rather than competition or isolation, is encouraged among students

Collaborative environments promote collaboration among students and enhance their skills triggered by learning within a group or learning in a virtual environment technology. Students are able to join actively in the construction of knowledge, helping in the creation, exchange and analysis of information and interactions during the group's learning OOP. Some benefits include private collaborative problem solving [10]:

- Encourage students to verbalize their thinking;

- To encourage students to work together;

- Ask questions;

- Explain and justify their opinions;

- Students grow responsibility for their own learning and increase the possibility of solving problems or examine a variety of ways.

The collaborative learning has proven to be potential to improve critical thinking, the thought of drafting, social communication skills such as leadership, decision making, trust building and conflict management. In years of research to develop customized systems, the results has influenced the field of educational software [11].

\section{Redu Educational Social Network: Teaching OOP}

The social and educational software ${ }^{1}$ Redu, or simply Redu, is seeking an environment designed to meet a number of phenomena that occur in the processes of teaching and learning. The interface of Redu reflects the structures of teaching practice, from planning, through mediation processes of collaborative learning, to the assessment activities, monitoring and evaluation [12].

The adoption of Redu as a collaborative and mediation environment has positive consequences for the relationship between teachers and students [21]. On one hand, the teacher has the option of approaching the culture of younger generations, which opens a channel of communication fun and productive. Thus, the interaction time with each student may be higher, depending on the need of each. On the other, the relationship between teachers and students transforms from 'one to one' into 'one to many' relations [12].

The use of a social network for teaching OOP aims to seek and develop new forms of collaboration and communication. That can help students in the development of logical reasoning and problem solving. Thus, teaching OOP occurs collaboratively, leading students to situations where they were led to questions, problems and situations to solve problems with their peers, mediated by the teacher.

\section{Method}

The experiment was divided into three stages. The first one was composed by training teachers and students to use Redu. In the second step was initiated using the social software Redu by two professors of OOP. During this step, we observed the use of the platform by users. In the last step, we performed a semi-structured interview with teachers participating in the experiment.

\subsection{Participants}

Two teachers (P1 and P2), the disciplines of Object Oriented Programming, acting course Higher Degree in Computer Science from Federal Institute of Science and Technology of Tocantins-Campus Porto Nacional participated in this experiment.

Students of research are between from 18 to 40 years old. Regarding the length of use of computers, $20 \%$ of students have already been using computers for more than 5 years, $60 \%$ have used no more than 5 years and at least 1 year, and $20 \%$ for less have used more than 1 year. All the students participating in the research has used at least one of these social networks: Twitter, Orkut, Facebook.

\subsection{Procedures}

\footnotetext{
${ }^{1}$ http://www.redu.com.br
} 
A class of thirty (30) students (An) of college degree in computing enrolled a face-to-face object oriented programming course. The discipline of object-oriented programming was complementary structured in the Redu platform attending the school proposals, but also benefit of opportunities to collaborate through synchronous and asynchronous communication and to simulate algorithms through a JAVA API. Application programmer interfaces (APIs) that deal not in terms of functions but in terms of objects [22].

\subsection{Data Analysis}

For the analysis and categorization of data we adopted the qualitative analysis software NVivo ${ }^{2}$. This tool helped the data categorization process and the elaborating of hierarchy of categories as a tree. Data analysis was developed through a process of construction of categories or themes, that: "capture repeated patterns in most of the data collected." [14].

Analysis of the interactions was performed using thematic categories created retrospectively. Categories are created according the repeatedly occurring situations identified in the collected data. They represent the various issues discussed by the teachers throughout the course of object-oriented programming.

Data analysis includes description and interpretation of the different facets of phenomena being investigated. The final interpretation underwent the hardships and needs experienced by the teachers during the teaching using Redu platform.

\subsection{Requirements Elicitation}

After data collection and categorization, it will be proposed requirements arising from the teachers' needs to build prototypes of new interface to Redu, suggesting changes to be implemented in a new version of the system. The new design suggested should incorporate features that help reduce teachers' efforts and improve the effectiveness of their teaching activities.

\section{Results}

In this section, we present the main indications of the structure of the forms of collaboration and interaction during the learning process of object-oriented programming mediated Social Network Education-Redu. Finally, the main requirements will be listed Durantes identified the stage of data analysis.

\subsection{Peers Interaction: Collaboration}

According to the subjects involved in the study, Redu makes possible efficient peer interaction through their communication tools. Regarding the question of the initiative, all subjects stated that in Redu, they participated actively and without shyness.

The flexibility to join activity at any time outside the classroom provides greater collaboration among students and teachers. This type of asynchronous communication available in Redu facilitated the participation of all. The

\footnotetext{
${ }^{2}$ Nvivo, research software for analysis and insight, www.qsrinternational.com
}

extra time to research, study and reflection contributes to a qualitative improvement in the subjects' participation in the interaction and improves the quality of contributions.

Teachers evaluated as positive the extra time for interaction outside the time in the classroom. They could have more time to solve students' doubts and always provide a constructive debate.

Students' interaction in Redu felt the desire of join a study group. There was a paradigm shift because teachers were previously seen as an element of the participant group research.

In the study of [15], the authors observed evidence that the teacher was seen by students as someone who was in the environment to assist them in the learning process, coming to assume a role of facilitator of the learning process as shown in Figure 1.

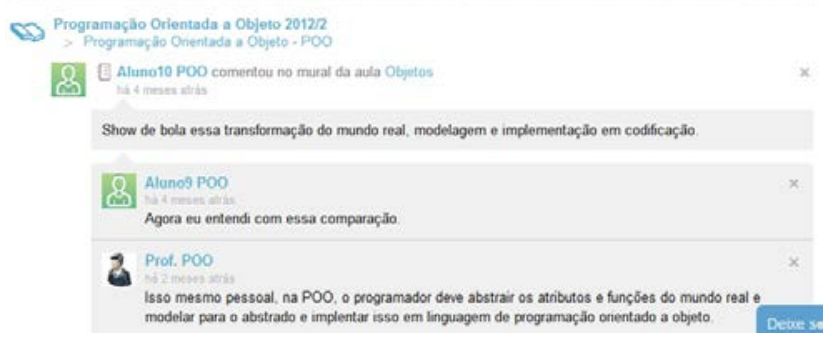

Figure 1. Interaction of Students and Professor OOP

In the study by [15] observed evidence that the teacher was seen by students as someone who was in the environment to help them in the learning process, and therefore takes on the role of facilitator of the learning process.

\subsection{Simulator Inside the Social Software: Innovation in the OOP Teaching Environment}

The API (Application Programming Interface) documentation of Redu is available at http://developers.redu.com.br. It aims to enable the integration of external software simulators in a in a simple and transparent way.

Through an API, a compiler was integrated in Redu and students could simulate algorithms using this application. In the same virtual learning environment could view the multimedia contents of the discipline and object-oriented programming without the need to use or install an IDE (Interphase Development) specific.

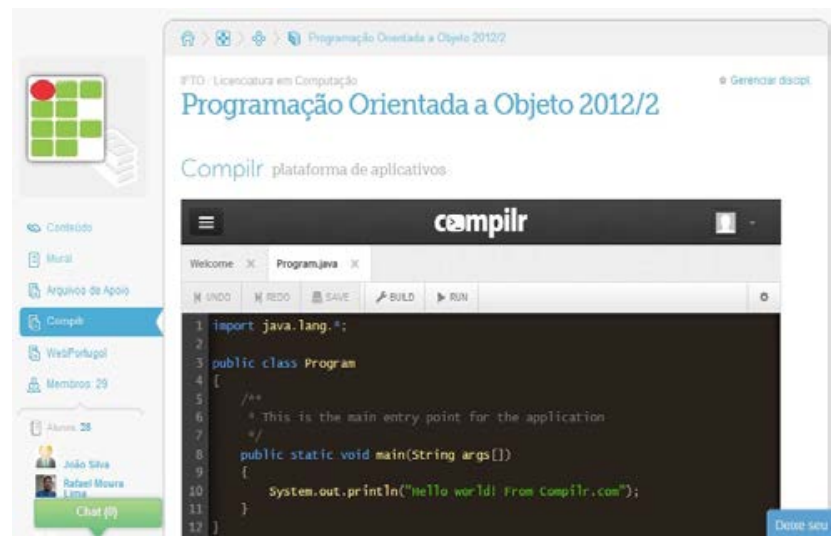

Figure 2. Java API available in the Educational Social Network 
We observed a qualitative gain in learning. The Redu proved innovative as it gave the teacher a new methodology of teaching OOP outside of the classroom. Students could view the content of programming through another point of view and could stimulate collaboration between students and faculty. It was shown how the teacher could innovate in their practice creating new forms of interaction, including promoting interaction with students outside the classroom [16].

\section{Discussion}

In this section we present the requirements identified and generated from the data analysis to improve the educational social network Redu to teache object-oriented programming. The main objective will be to suggest changes to be implemented in a new version of Redu.

Summary of needs mentioned by the teachers in the process of preparation, teaching and evaluation:

- Uploading Java Class for a specific class

- Collaborate the same Java code while

- Establishment of a common interest in Group Redu

- Assessment with open questions

- Sending e-mail to all students of

- Uploading e-mail to students of a course

- Insert link in the message board course

- Mobility between course modules

- Create dependency between modules for student

\section{Conclusions}

This paper aims to present evidence that the platform Redu can be effective as a mediator platform for teaching OOP. We conclude that Redu proved to be a good option in the process of planning, teaching and assement of the syllabus of object oriented programming. That's because it is transparent to the realization of practical communication, providing mutual aid, simplification in the form of verbal communication. This set of factors facilitate collaborative learning and didactic teaching mediation in the context of a virtual learning network. It may help to promote reflection on teaching practice and changes in the relationship between teacher and student, thus creating new social relations.

\section{Acknowledgement}

I thank Federal Institute of Education, Science and Technology of Tocantins-Porto Nacional campus and Capes.

\section{References}

[1] Doube, W (2000), "The impact on Student Performance of a Chance of Language in Sucessive Introductory Computer Programming Subjects”, Proceedings of the Australian Conference on Computing Education (ACE 2000) (Melbourne, Australia), Decembrer 2000. New York, Ny: ACM Press.
[2] Vahldick, A. (2007), "Uma Experiência Lúdica no Ensino de Programação Orientada a Objetos”, XVIII Simpósio Brasileiro de Informática na Educação. São Paulo, SP, Brasil.

[3] Kölling, M., 1999, "The Problem of Teaching Object-Oriented Programming, Part 1: Languages," Journal of Object-Oriented Programming, 11 (8): 8-15.

[4] Anquan, Jie \& Yuqing, Li \& Bailiang, Chen \& Jihua, Ye \& Jie, Zou. (2010), "The Education Reform and Innovation of Object oriented Programming Course in Normal University", The 5th International Conference on Computer Science \& Education. IEEE.

[5] Li Liu \& Jiang Liu \& Hong Zhuang \& Zhaoqing Wang. (2009), "LCM Exploration and Practice”, In OOP Teaching. International Conference on Scalable Computing and Communications; The Eighth International Conference on Embedded Computing. IEEE.

[6] Tucker, A. \& Deek, F. e Jones, J. \& McCowan, D. \& Stephenson, C. \& Verno, A. (2003), "A model curriculum for k-12 computer science: Final report of the ACM k-12 task force curriculum committee", New York, NY: The Association for Computing Machinery.

[7] Baloche, L. (1998), “The cooperative classroom: Empowering learning”, Upper Saddle River, NJ: Prentice Hall. IEEE.

[8] Safia, A., Mala. (2012), "T. Ascertaining the More Knowledgeable Other among peers in Collaborative E-Learning Environment", IEEE-Fourth International Conference on Advanced Computing, ICoAC 2012 MIT, Anna University, Chennai. December 13-15.

[9] Kessler, G. and Bikowski, D. (2010), "Developing collaborative autonomous learning abilities in computer mediated language learning: Attention to meaning among students in wiki space. Computer Assisted Language Learning”, 23 (1): 41-58.

[10] Baghaei, N., Wade, V., Ashman, H., and Smyth, B. (2006) "Adaptive Hypermedia and Adaptive Web-Based Systems", volume 4018 of Lecture Notes in Computer Science. Springer Berlin Heidelberg, Berlin, Heidelberg.

[11] Tsiriga, V. e Virvou, M. (2004), "A framework for the initialization of student models in web-based intelligent tutoring systems. User Modelling and User-Adapted Interaction”, vol. 14, no. 4, pp. 289-316, 2004, 42 (3): 289-316.

[12] Gomes, A. S., Rolim, A. L., Silva, W. M. (Eds.). (2012), "Educar com o Redu”, Recife: Redu Educational Technology, 103 p.

[13] Ludke, Menga; André, Marli (1986), "Pesquisa em Educação: Abordagens Qualitativas”, São Paulo: EPU, p. 2.

[14] MERRIAM, S. 1998. Qualitative research and case study applications in education. San Francisco (USA): Jossey-Bass. p. 179.

[15] Gomes A. S.; Souza, F. V. C.; Abreu, J. A. B.; Lima L. C. C.; Melo, C. A.; Paiva, G. L.; Duarte, A. P. (2011), "Colaboração, Comunicação e Aprendizagem em Rede Social Educativa”, In Xavier A. C. (Ed.) Hipertexto e Cibercultura: links com a literatura, a publicidade, o plágio e as redes sociais educacionais, São Paulo: Respel.

[16] Vygotsky, L. S. (1978), "Mind in society, the development of higher psychological processes", Cambridge, MA: Harvard University Press.

[17] Gil, Antonio Carlos. (2008), "Como elaborar projetos de pesquisa”, 5. ed. São Paulo: Atlas.

[18] Li, Longshu; Xu, Yi. 2010. The Teaching Research on a Case of Object-Oriented Programming. The 5th International Conference on Computer Science \& Education.

[19] Vessey, I., \& Conger, S. A., (1994). Requirement specification: learning object, process, and data methodologies. Communications of the ACM. 37 (5), 102-113.

[20] Lopes, Mauricio Capobianco. iPoo: a methodology for the introductory teaching of object orientation. Computing SeminarRS (SEMINFO RS'2007). I Tchê WEI - Workshop on Computing in Education.

[21] Gomes A. S.; Souza, F. V. C.; Abreu, J. A. B.; Claudeivan, L. (2011), Análise das Práticas de Colaboração e Comunicação: Estudo de Caso utilizando a Rede Social Educativa Redu, XXII SBIE-XVII WIE.

[22] J. Gosling, B. Joy, and G. Steele. The Java Language Specification. Addison Wesley, 1996. 